\title{
Internet Application and Technology for E-Government Public Services
}

\author{
Sara Jeza Alotaibi \\ Institute of Public Administration, Saudi Arabia
}

\begin{abstract}
Regardless of whether we are referring to those run online or within administrative offices, there is a high demand for government services, and such a demand has been attempted to be fulfilled via the implementation of a variety of online approaches that also aim to not compromise on the quality and speed of such service provision. Ultimately aiming to evaluate Architecture of E-Government public services alongside any other new web-based innovations in the context of their usefulness within government sectors, this paper will summarise and weigh up the past and future of online applications (beginning with Web1, Web2, and SemanticWeb3). Furthermore, this document will also provide some insight into any previous government web-based initiatives that have ultimately succeeded in furthering their productivity.
\end{abstract}

\section{Introduction}

Ultimately leading to a new and improved way of operating within government sectors by allowing such services to be more easily obtained, E-Government has the potential to drastically enhance government performance; this probable due to the fact that EGovernment implements relevant ICT software to enhance cost-effectiveness, honesty, and selfresponsibility within such operations. Furthermore, EGovernment differs fundamentally to traditional government agencies, as it provides delivery systems that are not 'tiered' nor straightforward. In turn, this allows such services to be better adapted to each individual they provide to, allowing for enhanced, personable service [1].

Indeed, it is important to acknowledge that a very large number of countries are currently understanding the benefits of E-Government and thus are implementing it as a way to obtain their own individual goals; such countries have identified EGovernment as a more well- rounded structure to that of their original governmental practices, thus furthering their economy and efficiency [2]. Such implementation lends the way to the big shift to WebOriented Architectures (WOA) from ServiceOriented Architectures (SOA), such a shift potentially resulting in the newfound ability to provide any given individual with their requested governmental assistances, no matter where they are. It is with this in mind that, as a way to allow for more successful collaboration, a variety of public districts are currently adopting newly introduced technologies [7-10].

Notably, despite the fact that the significant rise in the amount of social network website users in recent years has resulted in similarly drastic E-Government service enhancements, it seems that the most advantageous aspect of E-Government is its ways of going about such transformations. It is this that has lent the way to advancements in technologies such as Web1, Web2, and Web3, which have, in some ways, altered the entire workings of the Internet [4][11].

One such tactic being that of the implementation of social network applications, the government has adopted a variety of strategies in order to 'renovate' itself, and it is tactics such as these that have formed the core of E-Government's workings [3]. Furthermore, considering Web3 actually stemmed from Web2, Web3 is a rather novel idea-although Web1 and Web2 have, indeed, been implemented by a variety of sectors, as they are a cheap means of communicating with their people. In order to fully launch Web3, all Web2's elements in terms of intelligent retrieval, data integration, user-interest modelling, and semantic annotation (amongst others) are being melded so as to ensure Web3 is a clever, tailored, trustworthy programme to use.

In order to enhance their connections with their people, as well as to receive their comments on their workings, a variety of public companies are building upon their presence within social media platforms as a result of their acknowledging Web1, Web2, and Web3's capability for such things. Particularly when it comes to those living in rural areas and younger citizens, such novel technologies, such districts are also recognising such platforms can also allow the government to interact with a typically 'unreachable' category of citizen [5-6]. This, however, isn't where these applications' benefits end: they also allow for teaching citizens about governmental topics, the spreading of data across public services, the employment of co- producers, and the garnering of citizen feedback - all in an efficient, financially sustainable manner. Indeed, as a growing number of governments start capitalising in novel web-based applications to allow for new and improved citizen interaction, this novel method of participation allowed for by such platforms is additionally growing. Such a growth is also largely down to governments 
incorporating transparency within their priority list, as such programmes indeed allow for frequent, accessible communication with citizens-whether that be so they can ask about questions about public spending, the services offered, or the initiatives they are currently working on.

Considering the primary emphasis of this document concerns Web2, Web1, and Web3 in the context of E-Government public services, it is within Section 2 that one can find an array of background information concerning such platforms, Section 3 meanwhile summarising Architecture of EGovernment public services and, finally, Section 4 putting forward a conclusion to the paper.

\section{Background Information of Web1, Web2, and Web3}

Whilst there has additionally been an array of conversation about government and business implementation of Web2 in recent years, there has also been a lot of talk concerning Web1, Web2, and Web3 within media platforms specifically, and their widespread use amongst younger people. Such an ICT development being triggered as a result of the Internet's shift from one simple tool to its own platform unto itself, Web2 can be described as somewhat of a trend within this sector allowing for the spreading of data, the encouragement of creative endeavours, and partnerships between consumers. Furthermore, upon comparing Web1 and Web2, we can say that the latter (also referred to as the New Internet) provides a more dense, practical, cooperative, and smooth-running experience compared to Web1, whose framework is rather basic in nature [9-14].

Notably, when we refer to Web2, what we are actually referring to is a novel social Internet- based platform allowing for the spreading of data, the encouraging of creative endeavours, and user partnerships; and it is with this tool that accessibility and intricacy are achieved amongst Wikipedia pages, blogs, and social media platforms (e.g., Facebook; MySpace) [11]. Indeed, it is with the aid of Web2 that users can create any kind of content they desire and share it on such platforms with no complicationsand it is through such sharing that we can really pinpoint a sense of community and partnership within the online sphere. From the above, we can witness Web1 being expanded via Web2, allowing not just for the consuming but for the creating of data [13].

Going back to our comparison of Web2 to Web1, the former's features were primarily created by Tim O'Reilly (2004), and its users are many and widespread. Indeed, in regard to their proficiency in having their users' interests at heart, triggering positive change, and to fully engage its users, Web2 seems to be consistently achieving a high level of performance - and this is only increasing as more people start using its features [12]. Such high use has also lent the way to 'mashup' apps, such as those of chatrooms, blogs, podcasts, Really Simple Syndication (RSS), etc. - all of which also being key elements to the procedure of E- Government sitebuilding. It is with all of the above in mind that any given government simply has to acknowledge Web2's growing essentiality today in order to move forward and improve [3-5].

Whilst Web2 is oftentimes referred to as New Internet, Web3 is, by a similar token, dubbed Future Web. This network, similarly to that Web2 did with Web1, integrates all the best features of Web2 into its own design and builds upon them, acting as the expanded version of cyberspace knowledge organisation and ontology technology [9-14]. Please see below for a summary of Web3's key components:

\subsection{High-Quality Information Content Services}

Web3 ensures there is an equilibrium between user access and content in order to ensure the service provided is a suitable one, this is done via credible SNS formation, as well as that of easy-to-manipulate vlogs/blogs/Wikis. It is through such a process that data shared by high- level, trusted individuals will be given more credit, thus improving the software's own trustworthiness and integrity and users' experiences [10].

\subsection{High-Performance Information Integration}

In order to enable users to build upon their own units of information freely in line with their own curiosities, traits, education, and necessities, it is the 'mashup' [9] approach, coupled with the use of the required software, that allows for the mixing of 'micro-content'.

\subsection{Personalised User Experience}

Thoroughly investigating users' data (which is handled by the platform) in order to formulate a relevant, personalised interest model, Web3 allows for a novel experience wholly designed to suit the user at hand; indeed, Internet users are now in a better position to access tailored services and to find relevant data quicker as a result of newly introduced features such as preference information processing tools and data mining [11].

\subsection{Intelligent Information Retrieval}

With the aid of references tools and AI, the formulation of a completely tailored search engine is possible; indeed, we can market computer and human 
computer communication via multi-agent tech, such actions likely lending the way to filtering, data collection, fusion, and clustering efficiency [13].

\subsection{Cross-Platform and Cross-Language Terminal Services}

One of Web3's main goals has been to merge communication services with the Internet as a way to ensure compatibility with PCs and a range of other devices - which has become more of a priority since the drastic improvement of mobile terminal apps. With this in mind, search scope can be extended, and data-sharing efficiency can be achieved through the use of Web3, as it offers cross-language information retrieval services [14].

\section{E-Government Public Service Architecture (Web1, Web2, and Web3-Based)}

Such adaptations having the potential to create an array of positive changes (e.g., enhanced communication between industries and businesses; enhanced government delivery services; improved government management; citizen's access to data), EGovernment can be loosely defined as 'government agencies' use of data technologies that possess the capability to transform business, citizen, and other arm of government links' [1-3]. Indeed, we can see that, through E-Government implementation, we can witness enhanced honesty in inner workings, a reduction in corruption, increased revenue, and higher accessibility, amongst other benefits. Indeed, as a tool to enhance its effectiveness and keep it up-to-date, the public sector reform has made E-Government an integral aspect after acknowledgement of the fact that it has the potential to considerably support the government in its journey of improvement [3-6].

Whilst Web3 (Semantic Web) has been founded on the grounds of service, Web1 was formulated for searching and Web2 was mainly created for social activities grounded on communication between users - and, indeed, it is the former network that has been constantly growing as a way to join the dots with the searched and received data. It is through such means that such information can be connected from source to source and, thus, to be fully comprehended by any given system. Furthermore, in turn allowing for the public's access to a tailored government system via devices such as phones, Web3 networks are compatible with multi-terminal services-also allowing for such information to be portable (i.e., able to be viewed 24 hours a day at any location). Furthermore, technological and hypothetical frameworks are being laid down upon the founding of Arabic-Chinese cross-language models founded on the grounds of topic map/Lucene and ontology. It is through such advancements that any social hurdles stopping some citizens from being able to benefit from such initiatives will be eradicated, making for an all-inclusive software [8-11].

Notably, semantic annotations (i.e., tools detailing the connections between ontological concepts and practical information) and semantic tags offer reliable, regular semantic associations and descriptions, thus allowing for the formulation of novel means of data sharing and finding. Indeed, semantic annotation can be regarded as a way in which individuals can contribute semantic data to preexisting data platforms founded on the grounds of specific ontology [20], such a tool improving information resource integration and building upon knowledge connections to allow for a more wellrounded learning experience [9].

It is additionally important to note that Government to Business (G2B), Government to Citizen (G2C), and Government to Government $(\mathrm{G} 2 \mathrm{G})$ are the three sections into which one particular approach to E-Government implementation are partitioned into [5-6]. Meanwhile, Web1-, Web2-, and Web3-based E-Government services can be classed, as previously briefly touched on, into the sections: Web-Oriented Architectures (WOA), Service Providers with Relying Party, Personalised User Portal, and Service-Oriented Architectures (SOA) (see Figure 1 for a representation of this).

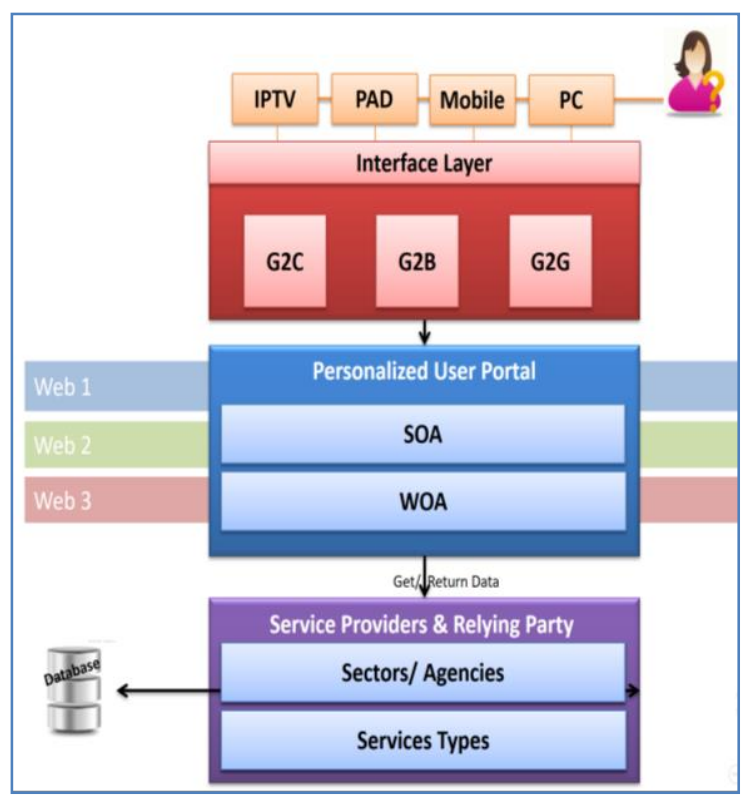

Figure 1. Web1-, Web2-, and Web3-based EGovernment services

\section{Conclusion}

Budget scarcity, institutional arrangements, sociocultural customs, and behaviour patterns amongst the public have been just some of the things 
preventing government initiative, thus meaning that E-Government innovation in terms of public services has, thus far, been rather slow-moving and cautious. Indeed, particularly when it comes to looking at this through a systematic lens, there are still some differences in opinion and attitude regarding changes from traditional to reformed practices. Saying this, Web2 and Web3 have been put forward with the best intentions (i.e., to move the government forward and create more future opportunities for the public), and it is with this in mind that this paper has showcased the differences between Web1, Web2, and Web3including those in terms of architecture and offered EGovernment public services.

\section{References}

[1] W. Dong, "Construction and Test of Web Service Solution for E-government," 2009 International Conference on Computational Intelligence and Natural Computing, Wuhan, 2009, pp. 221-224.

[2] C. Yin, S. Liu, L. Chen and X. Ye, "E-government Web Mining Tool Design and Implementation Based on the Semantic Web," 2008 IEEE/WIC/ACM International Conference on Web Intelligence and Intelligent Agent Technology, Sydney, NSW, 2008, pp. 240-243.

[3] Q. Guo, H. Zheng, G. Chang and J. Li, "High Availability and Flexibility of Web Services in the Egovernment System," 2009 WRI World Congress on Software Engineering, Xiamen, 2009, pp. 372-376.

[4] B. Al-Shargabi, "Security Engineering for EGovernment Web Services: A Trust Model," 2016 International Conference on Information Systems Engineering (ICISE), Los Angeles, CA, 2016, pp. 811.

[5] A. Adadi, M. Berrada, D. Chenouni and B. Bounabat, "Ontology based composition of eGovernment services using AI Planning," 2015 10th International Conference on Intelligent Systems: Theories and Applications (SITA), Rabat, 2015, pp. $1-8$.

[6] Y. Jinhua, L. Yong and Z. Peng, "E-government Evaluation Based on Citizen Satisfaction and its Implementation," 2010 International Conference on E-Business and E-Government, Guangzhou, 2010, pp. 535-538.

[7] J. Meng, S. Gao and L. Zhang, "The Community Website Design Based on Complementary Advantages of Web2.0 and Web1.0," 2008 4th International Conference on Wireless Communications, Networking and Mobile Computing, Dalian, 2008, pp. 1-4.
[8] L. Dong and J. Shangjie, "Website Construction Based on Web2.0 Technology," 2011 International Symposium on Computer Science and Society, Kota Kinabalu, 2011, pp. 3-6.

[9] H. M. Dahlan, Ismail Mohamed Ali and A. R. C. Hussin, "Suitability of Collaborative Learning activities in Web 2.0 environment," 2010 International Conference on User Science and Engineering (i-USEr), Shah Alam, 2010, pp. 65-70.

[10] P. Zhou, "Discussion on precision network marketing base on Web3.0," 2011 International Conference on E-Business and E-Government (ICEE), Shanghai, China, 2011, pp. 1-3.

[11] H. Cui-hong, "Research on Web3.0 Application in the Resources Integration Portal," 2012 Second International Conference on Business Computing and Global Informatization, Shanghai, 2012, pp. 728-730.

[12] Nasution, M. K. M. (n.d.). Social network extraction based on Web: 1. Related superficial methods. IOP Conference Series: Materials Science and Engineering, 300(1).

[13] Kay, M. (n.d.). Changing the world wide web, one language at a time. EContent, 41(3), 12-13. Retrieved from http://search.ebscohost.com.sdl.idm. oclc.org/login.aspx?direct=true $\& \mathrm{db}=$ edselc $\& A N=e d$ selc.2-52.0-85058240607\&site=eds-live

[14] Vaishnav, R. S. (n.d.). Integration of web 2 technologies for ODL (Vol. 3). IGI Global. 